\title{
The Investigations of Chondritic Meteorites by X-ray Diffraction and Mössbauer Effect Methods
}

\author{
A. Ludwig, W. Zarek And E. Popiel \\ August Chełkowski Institute of Physics, University of Silesia \\ Uniwersytecka 4, 40-007 Katowice, Poland
}

\begin{abstract}
The Mössbauer spectroscopy and X-ray diffraction techniques were used to investigate the mineral and magnetic fractions of two meteorites: carbonaceous chondrite named Allende (CV3) and ordinary chondrite - El Hammami (H5). The investigations of a powder mixture of chondrules and matrix show that the meteorites studied contain iron mainly in the silicates, olivine, and pyroxene. The metallic fractions of the El Hammami meteorite contain the ferromagnetic mineral kamacite (bcc iron-nickel alloy). This phase with cubic symmetry was identified by symmetric Mössbauer spectrum with disturbance in relative line intensities. The results suggest that the Allende meteorite does not contain a pure metallic phase.
\end{abstract}

PACS numbers: 61.18 .Fs

\section{Introduction}

The meteorites called chondrites are the least altered samples of the material which evolved into our system of planets. Almost all chondrites contain chondrules - spherical inclusions which were most probably formed from small grains of condensed gas during cooling of the solar nebula [1].

The Allende carbonaceous chondrite is classified as CV3 and it represents some of the oldest known matter, which was formed 4.65 billion years ago. The Allende fell at 1:05 AM on February 8th, 1969 in Pueblite de Allende, Chihuaha State, Mexico $\left(26^{\circ} 58^{\prime} \mathrm{N}, 105^{\circ} 19^{\prime} \mathrm{W}\right)$. The original mass of this meteorite is estimated to be several tones. To date over two tones have been recovered, i.e., more than $80 \%$ of the total known carbonaceous chondrite material [2].

El Hammami meteorite is a type $\mathrm{H} 5$ ordinary chondrite which was found in Tiris Zemmour, Mauretania $\left(23^{\circ} 17^{\prime} \mathrm{N}, 10^{\circ} 49^{\prime} \mathrm{W}\right)$ in 1997 . The meteorite fell most 
probably in January 1995. Its total known mass is estimated at about $240 \mathrm{~kg}$. The fall of the El Hammami meteorite was reported in [3]. One meteoritic sample $(3.5 \mathrm{~g})$ was derived from the collection of the Astronomical Observatory in Olsztyn, Poland.

In the present article we describe the results of the X-ray diffraction measurements and Mössbauer effect investigations of two meteorites of type CV3 and H5. The main aim of these investigations was to determine the mineralogical composition of the meteorites studied.

\section{Experimental}

The investigations were made on powdered samples. The powder was separated into metallic and mineral fractions by using a magnet.

The X-ray diffraction measurements were carried out using a high-resolution Siemens diffractometer $(\theta-\theta)$ D 5000 with $\mathrm{Cu} K_{\alpha}$ radiation. Qualitative phase analysis employed the "Diffract AT Search/Match Program" [4] and the data base from International Center for Diffraction Data (JCPDS-ICDD).

For each meteorite specimen the Mössbauer spectra were recorded at room temperature with a conventional constant acceleration spectrometer of the Polon type. The source was ${ }^{57} \mathrm{Fe}$ in Pt. The spectrometer was calibrated with the use of the standard $\alpha$-Fe absorber at room temperature in the velocity range $\pm 11 \mathrm{~mm} / \mathrm{s}$. The Mössbauer parameters were obtained by an iterative curve fitting procedure used by MOS program. The mineralogical analysis of spectra was based mainly on Ref. [5].

\section{Results of experiments and discussion}

The X-ray diffraction patterns of powder from mineral parts of the meteorites investigated are shown in Figs. 1a, b. It is clearly seen that the meteorites
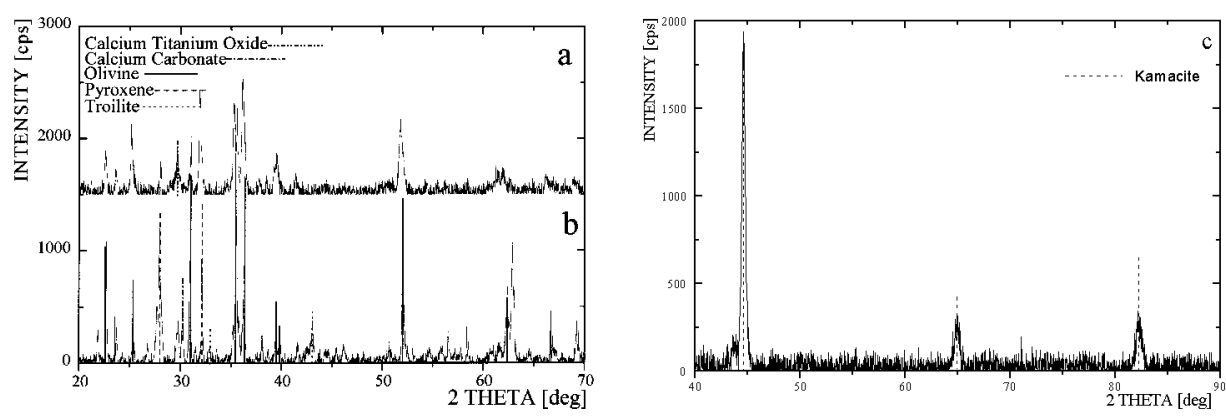

Fig. 1. X-ray diffraction patterns of the meteorites investigated: (a) the Allende meteorite (mineral part), (b) the El Hammami meteorite (mineral part), (c) the El Hammami meteorite (metallic part). 
TABLE I

Qualitative phase analysis of the mineral and metallic parts of the meteorites investigated.

\begin{tabular}{l|c|c}
\hline \hline Meteorite & Minerals & Chemical formula \\
\hline \multirow{2}{*}{ Allende } & olivine & $(\mathrm{Mg}, \mathrm{Fe})_{2} \mathrm{SiO}_{4}$ \\
& pyroxene & $\mathrm{MgSiO}_{3}$ \\
& calcium titanium oxide & $\mathrm{Ca}_{2} \mathrm{Ti}_{2} \mathrm{O}_{6}$ \\
\hline \multirow{2}{*}{ El Hammami } & olivine & $(\mathrm{Mg}, \mathrm{Fe})_{2} \mathrm{SiO}_{4}$ \\
(mineral part) & pyroxene & $\mathrm{MgSiO}_{3}$ \\
& troilite & $\mathrm{FeS}$ \\
\hline El Hammami & calcium carbonate & $\mathrm{CaCO}_{3}$ \\
(metallic part) & kamacite & $\mathrm{Fe}-\mathrm{Ni}$ alloy $(<7.5 \% \mathrm{Ni})$
\end{tabular}

studied are multiphase systems. The qualitative phase analysis of mineral fractions of both meteorites shows the presence of the diffraction lines originating mainly from mineral olivine $(\mathrm{Mg}, \mathrm{Fe})_{2} \mathrm{SiO}_{4}$ richer in iron. The results of detailed phase identification are listed in Table $\mathrm{I}$.
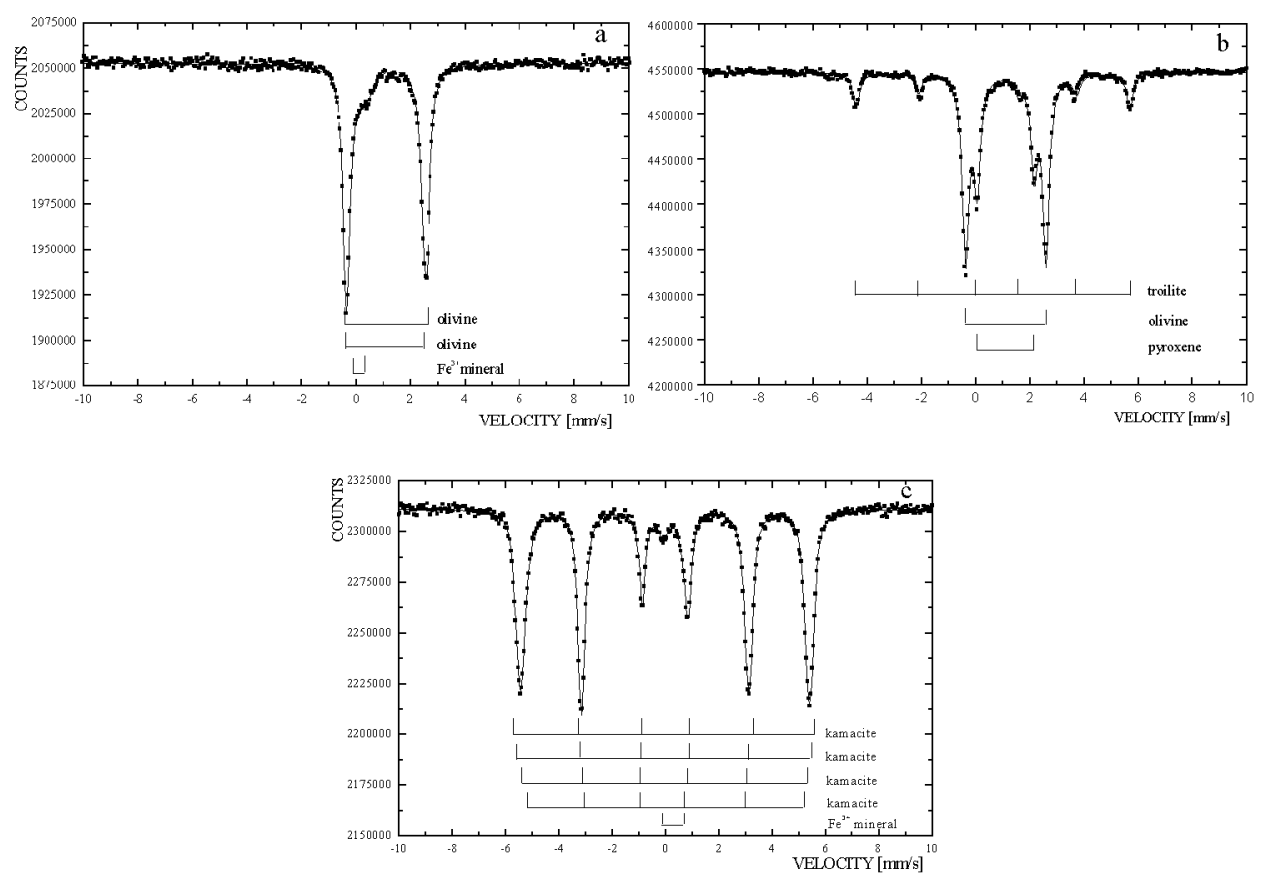

Fig. 2. Mössbauer spectra of the powdered samples from meteorites studied: (a) the Allende (mineral part), (b) the El Hammami meteorite (mineral part), (c) the El Hammami meteorite (metallic part). 
The narrow Bragg peaks in the diffraction pattern of the mineral part of the El Hammami meteorite suggest that this is material with high crystallinity. The lines observed that the diffraction pattern of the Allende meteorite are broadened because of poor crystallinity of the material. The X-ray diffraction measurements shows no evidence of the metallic phases in the Allende meteorite.

The metallic regions of the El Hammami meteorite (Fig. 1c) are composed of mineral kamacite, i.e. Fe-Ni alloy containing less than $7.5 \%$ Ni. Furthermore, a few not identified, very weak peaks were observed in the diffraction pattern. These lines correspond probably to the oxidized iron which was produced by oxidation in the terrestrial atmosphere.

The Mössbauer spectrum of the carbonaceous chondrite Allende is shown in Fig. 2a. The spectrum was fitted to three doublets. The two doublets originate from $\mathrm{Fe}^{2+}$ in olivine and one quadrupole doublet originates from iron containing compounds in the oxidation state +3 . The calculated values of the isomer shifts and quadrupole splittings are comparable with the published values [6]. The results of the Mössbauer investigations confirmed that the fragment of the Allende meteorite examined does not contain ferromagnetic minerals such as: magnetite, troilite, or $\mathrm{Fe}-\mathrm{Ni}$ alloys.

The Mössbauer spectrum of the El Hammami meteorite (a mineral part) is shown in Fig. 2b. It consists of two strong paramagnetic doublets which correspond to $\mathrm{Fe}^{2+}$ in pyroxene $(\mathrm{Mg}, \mathrm{Fe}) \mathrm{SiO}_{3}$ (smaller quadrupole splitting) and to $\mathrm{Fe}^{2+}$ in

\section{TABLE II}

Room temperature Mössbauer parameters of the mineral and metallic parts of the meteorites investigated. IS - isomer shift (relative to metallic iron), QS - quadrupole splitting, $H$ - hyperfine field and $A$ - relative area of the components $[5,7]$.

\begin{tabular}{l|c|c|c|c|c}
\hline \hline & $\begin{array}{c}\text { Parameters } \\
\text { Mineral }\end{array}$ & $\begin{array}{c}\text { IS } \\
{[\mathrm{mm} / \mathrm{s}]}\end{array}$ & $\begin{array}{c}\text { QS } \\
{[\mathrm{mm} / \mathrm{s}]}\end{array}$ & $\begin{array}{c}H \\
{[\mathrm{kOe}]}\end{array}$ & $\begin{array}{c}A \\
{[\%]}\end{array}$ \\
\hline \multirow{3}{*}{ Allende } & olivine & 1.13 & 2.86 & - & 68.11 \\
& olivine & 1.17 & 3.0 & - & 19.05 \\
& $\mathrm{Fe}^{3+}$ mineral & 0.3 & 0.2 & - & 12.84 \\
\hline El Hammami & olivine & 1.15 & 3.0 & - & 53.03 \\
(mineral part) & pyroxene & 1.15 & 2.1 & - & 26.33 \\
& troilite & 0.76 & 0.16 & 314.5 & 20.64 \\
\hline \multirow{3}{*}{ El Hammami } & kamacite & 0.02 & 0.04 & 349.9 & 9.6 \\
& kamacite & 0.02 & 0.01 & 340.5 & 38.25 \\
& kamacite & 0.01 & -0.01 & 332.9 & 34.17 \\
& kamacite & 0.02 & -0.06 & 323.9 & 11.98 \\
& Fe mineral & 0.4 & 0.8 & - & 6.03
\end{tabular}


olivine (larger splitting) together with a Zeeman sextet which attributes to the antiferromagnetic mineral troilite (stoichiometric FeS). Spectrum (c) in Fig. 2 is related to the magnetic fractions of the El Hammami meteorite. The spectrum is a superposition of four sextets connected with the Fe atoms surrounded by different number of $\mathrm{Ni}$ atoms. The Mössbauer parameters and their mineral identification are given in Table II. Moreover, the disturbance in relative line intensities $3: 2: 1: 1: 2: 3$ was observed in experimental spectrum. The one small doublet with low intensity $(\approx 6 \%$ ) was also fitted on the spectrum of this phase. The values of the isomer shift (IS $=0.4 \mathrm{~mm} / \mathrm{s}$ ) and quadrupole splitting (QS $=0.8 \mathrm{~mm} / \mathrm{s}$ ) are consistent with published values of iron weathering products in meteorites [8].

\section{Conclusions}

The results of investigations of the powdered samples including mineral grains and matrix show that the chondrites studied contain iron mostly in mineral olivine $\left((\mathrm{Mg}, \mathrm{Fe})_{2} \mathrm{SiO}_{4}\right)$. The $\mathrm{Fe}-\mathrm{Ni}$ alloy in the $\mathrm{El}$ Hammami meteorite contains mineral kamacite and oxidized iron formed after the meteorite has fallen to the Earth whereas the Allende meteorite does not contain any metallic phase.

\section{References}

[1] H.Y. McSween, Stardust to Planets. Geological Tour of the Solar System, 1st ed., St. Martin's Griffin, Frankfurt 1995.

[2] http:/www.alaska.net/ meteor/AMinfo.htm

[3] J.N. Grossman, The Meteoritical Bulletin, in press; Meteoritics and Planetary Science $\mathbf{3 3}$ (1998).

[4] Ch.S. Barret, J.V. Gilfrish, R. Jenkins, T.C. Huang, P.K. Predecki, Adv. X-ray Anal. 32, 531 (1989).

[5] Mössbauer Handbook Mineral Data, Mössbauer Effect Data Centre VNC, September 1983 .

[6] H. Roy-Poulsen, L. Larsen, N.O. Roy-Poulsen, L. Vistinsen, Phys. Scr. 23, 1113 (1981)

[7] H. Roy-Poulsen, M.L. Andersen, L. Larsen, N.O. Roy-Poulsen, L. Vistinsen, J.M. Knudsen, Phys. Scr. 26, 248 (1982).

[8] R.G. Burns, T.H. Burdine, D.S. Fisher, R.P. Binzel, Meteoritics 30, 625 (1995). 